\title{
A Müller's example to Cauchy problem: an operatorial point of view
}

IOAN A. RUS

\section{ABSTRACT.}

We present an operatorial point of view on a Müller's example to Cauchy problem.

DEPARTMENT OF MATHEMATICS

BABES-BOLYAI UNIVERSITY

KOGĂLNiCEANU 1, 400084 Cluj-NAPOCA, ROMANIA

E-mail address: iarus@math. ubbcluj.ro 